\title{
The clinical manifestations and treatment of male breast cancer: a report of three cases
}

\author{
Shuji Suehiro* (D), Miyuki Abe, Yohei Takumi, Takafumi Hashimoto, Mirei Kamei, Atsushi Osoegawa, \\ Michiyo Miyawaki and Kenji Sugio
}

\begin{abstract}
Male breast cancer is an extremely rare malignancy. We treated three male breast cancer patients. All three patients showed clinical NO and received sentinel lymph node biopsy. Because the sentinel lymph node was positive for metastasis in one patient, a total mastectomy with axillary lymph node dissection was performed. The other two patients were negative for sentinel lymph node metastasis, and a simple mastectomy was performed. Two of the patients were postoperatively treated with tamoxifen; another patient was treated with adjuvant chemotherapy using taxotere and cyclophosphamide before tamoxifen. There was no recurrence in any of the three patients during an average follow-up period of 56.7 months (range 11.8-80.3). A sentinel lymph node biopsy is recommended for node staging in both male and female breast cancer patients as it is associated with a lower incidence of complications.
\end{abstract}

Keywords: Male breast cancer; Mastectomy; Adjuvant therapy

\section{Background}

Male breast cancer $(\mathrm{MBC})$ is an extremely rare malignancy which accounts for $1 \%$ of all breast cancers and $0.1 \%$ of all male cancers [1]. In spite of the low incidence of $\mathrm{MBC}$, it is associated with a higher mortality than female breast cancer (FBC), due to the more advanced staging of patients at the time diagnosis [2]. In 2013, only 82 of the 13,230 patients in Japan who died as a result of breast cancer were males [3]. Because of the rarity of $\mathrm{MBC}$, its etiology is less clear than $\mathrm{FBC}$. The management of patients with MBC generally depends on the information from the diagnosis and the processes and treatments of FBC. However, in contrast to $\mathrm{FBC}$ patients who are more often treated with breastconserving surgery, most $\mathrm{MBC}$ patients are treated with simple mastectomy with axillary lymph node dissection (ALND) or sentinel lymph node biopsy (SLNB) [4-6]. We herein report three MBC cases with information on the diagnostic procedures and management, including the performance of SLNB.

\footnotetext{
* Correspondence: shuji5275@oita-u.ac.jp

Department of Thoracic and Breast Surgery, Faculty of Medicine, Oita University, 1-1 Idaigaoka Hasama-machi, Yufu, Oita 879-5593, Japan
}

\section{Case presentation}

SLNB: At the day before operation, sentinel lymphoscintigraphy was performed, with the injection of $99 \mathrm{~m} \mathrm{Tc}$ $(0.2 \mathrm{ml})$ using a Techne Phytate Kit. Sentinel lymph nodes (SLNs) were detected with a hand-held gamma probe (Navigator GPS, Sheen man, Osaka, Japan). When an excisional biopsy had already been carried out, subdermal injection was performed near the scar. Planar scintigraphic scans of the involved breast and the axillary region in the anterior and anterior-oblique projections were carried out after $4 \mathrm{~h}$ of injection.

Under general anesthesia, indocyanine green $(1 \mathrm{ml})$ was injected into the periareolar skin and periphery of tumor for SLNB by the dye method. SLNs were traced by the Navigator GPS and confirmed by the presence of a radioisotope and dye. The pathological diagnosis of the resected SLNs was performed during surgery.

\section{Case 1}

A 64-year-old man presented to his family doctor complaining of a tumor in his right breast that had been present for 2 years. A CT showed a round tumor of $10 \mathrm{~mm}$ in diameter under the nipple. There was no evidence of axillary lymph node swelling or metastatic disease (Fig. 1). Mammography (MMG) and ultrasonography (US) were not performed. An excisional biopsy was

\section{然 Springer}




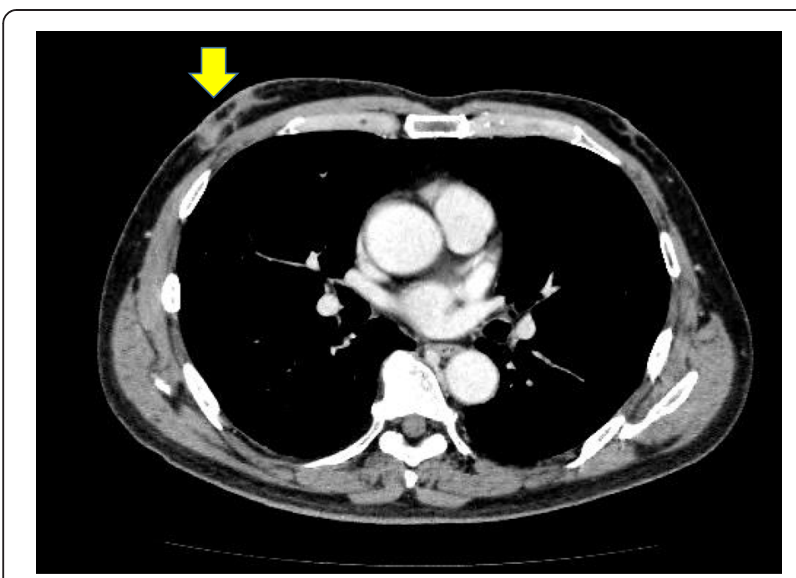

Fig. 1 A preoperative chest CT scan showing the incisional biopsy scar (arrow) of the right breast carcinoma

performed, which revealed an invasive ductal carcinoma with a close margin $(<5 \mathrm{~mm})$. He was introduced to our hospital for operation. The clinical diagnosis was cT1cN0M0, stage I. Because the pathological margin of the excisional biopsy was close $(<5 \mathrm{~mm})$, we explained to the merits and demerits of the different procedures (including partial mastectomy or total mastectomy), and an operation was selected. In our breast surgery department, MRI of the breast is usually performed for patients who intend to undergo partial mastectomy. We therefore performed total mastectomy and SLNB.

On the day before the operation, sentinel lymphoscintigraphy was performed. The SLNs were indicated by the combination of a radioisotope and blue dye. No metastasis was found in the intraoperative examination of frozen sections of four SLNs. After the SLNB, a total mastectomy of the right breast was performed. In the pathological examination of the SLNs, an H\&E staining showed no metastasis. The tumor was diagnosed as an invasive ductal carcinoma (histological grade 1, estrogen receptor (ER)-positive, progesterone receptor (PR)positive, HER2 0). The final diagnosis was pT1bN0M0, stage I. Because of the ER and PgR positivity of the tumor, the patient was treated with tamoxifen $(20 \mathrm{mg})$ for 5 years (Table 1). The patient did not suffer any complications and remains alive without any recurrent disease at 80.3 months after the surgery.

\section{Case 2}

A 64-year-old man visited to our hospital complaining of a tumor in his left breast that had been present for at least 3 months. A US scan showed a well-defined round tumor measuring $16 \mathrm{~mm}$ in diameter under the nipple (Fig. 2a). A cytological analysis of a fine needle aspiration biopsy specimen suggested malignancy. A CT scan showed a round tumor of $16 \mathrm{~mm}$ in diameter under the nipple without axillary lymph node swelling or distant metastasis (Fig. 2b). MMG were not performed. The clinical diagnosis was cT1cN0M0, stage I. On the day before the operation, sentinel lymphoscintigraphy was performed. Under general anesthesia, SLNB was performed by the radioisotope and dye method. The pathological diagnosis of the resected SLNs was conducted during surgery. No metastasis was found in the intraoperative examination of frozen sections of the two SLNs. After the SLNB, a total mastectomy of the left breast was performed. The tumor was diagnosed as an invasive ductal carcinoma (histological grade 1, ER-positive, PR-positive, HER2 0, Ki67 index $22.3 \%$ ). The pathological examination of the SLNs showed no signs of metastasis. The final diagnosis was pT1cN0M0, stage I. Because of the ER and PgR positivity of the tumor, the patient was treated with tamoxifen $(20 \mathrm{mg})$ for 5 years. The patient did not suffer any complications and remains alive without any recurrent disease at 78 months after surgery.

\section{Case 3}

A 69-year-old man presented to his family doctor complaining of a tumor in his right breast that he noticed a few days before his presentation. A US scan showed a well-defined round tumor of $25 \mathrm{~mm}$ in diameter under the nipple (Fig. 3a). A core needle biopsy suggested invasive ductal carcinoma. A CT scan showed a tumor of $24 \mathrm{~mm}$ in diameter under the nipple without axillary lymph node swelling or distant metastasis (Fig. 3b). He was referred to our hospital for surgery. The clinical diagnosis was cT2N0M0, stage IIA. On the day before operation, sentinel lymphoscintigraphy was performed. SLNB was performed by the radioisotope and dye method. A pathological examination of the three removed SLNs was conducted pathological during surgery, which showed metastasis in one SLN. After SLNB, a

Table 1 The clinical and pathological characteristics of three male breast cancer patients

\begin{tabular}{|c|c|c|c|c|c|c|c|c|c|c|c|c|c|}
\hline Case & Age & Tumor size (mm) & T & $\mathrm{N}$ & M & Stage & Histology & Nuclear grade & ER & $\mathrm{PgR}$ & HER2 & Ki67 & Adjuvant therapy \\
\hline 1 & 64 & 10 & 1 & 0 & 0 & I & Solid-tubular carcinoma & 1 & + & + & 0 & Unknown & Tamoxifen 20 mg \\
\hline 2 & 64 & 16 & 1 & 0 & 0 & । & Solid-tubular carcinoma & 1 & + & + & 0 & Unknown & Tamoxifen 20 mg \\
\hline \multirow[t]{2}{*}{3} & 69 & 24 & 2 & 1 & 0 & $\| \mathrm{B}$ & Scirrhous carcinoma & 3 & + & + & 0 & $21.2 \%$ & $\begin{array}{l}\text { Taxotere }\left(75 \mathrm{mg} / \mathrm{m}^{2}\right) \\
\text { and cyclophosphamide } \\
\left(600 \mathrm{mg} / \mathrm{m}^{2}\right)\end{array}$ \\
\hline & & & & & & & & & & & & & Tamoxifen (20 mg) \\
\hline
\end{tabular}



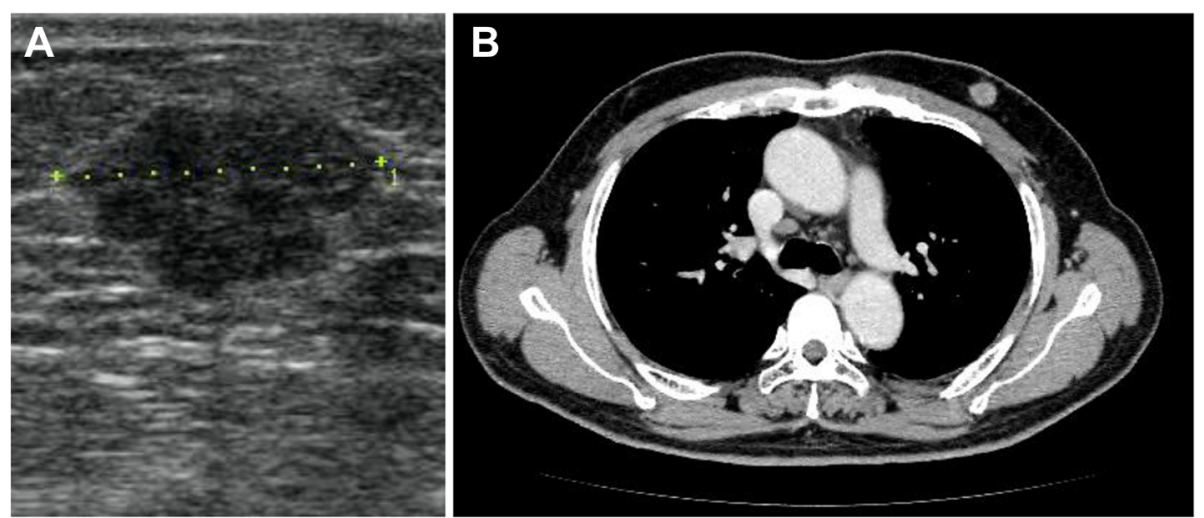

Fig. 2 a A preoperative US scan showing a round mass of $16 \mathrm{~mm}$ in diameter in the left subareolar area. b A preoperative chest CT scan showing a round tumor of $16 \mathrm{~mm}$ in diameter in the left subareolar area

total mastectomy of the left breast was performed with level II axillary lymph node dissection. The tumor was diagnosed as an invasive ductal carcinoma (histological grade 3, ER-positive, PR-positive HER2 score 0, Ki67 index $21 \%$ ). A pathological examination showed metastasis in 2 of 15 axillary lymph nodes. The final diagnosis was pT2N1M0, stage IIB. Adjuvant chemotherapy, consisting of taxotere (75 mg/m $\mathrm{m}^{2}, 120 \mathrm{mg} /$ body), and cyclophosphamide $\left(600 \mathrm{mg} / \mathrm{m}^{2}, 1000 \mathrm{mg} /\right.$ body $)$ was administered in four courses following the standard treatment guidelines for FBC. Adjuvant chemotherapy without anthracycline was administered because of the patient's hypertension. After chemotherapy, he was treated with tamoxifen $(20 \mathrm{mg}$ ) due to the ER and PgR positivity of the tumor. The patient experienced axillary paresthesia, a decreased range of motion of the shoulder and arm, but has experienced no recurrence in the 10 months since surgery.

\section{Discussion}

$\mathrm{MBC}$ is a rare malignant tumor, which accounts for less than $1 \%$ of breast cancer cases [1]. The median age at diagnosis among $\mathrm{MBC}$ patients is $67-71$ years, slightly older than the median age of 61 years in female patients $[7,8]$. Because MBC tumors are likely to express ER and PgR, the use of adjuvant hormonal therapy is beneficial [5]. Some reports have suggested that the frequency of high expression human epidermal growth factor 2 (HER2) is low [9-11]. In this study, all three patients showed ER-positive and HER2 scores of 0 and were treated with tamoxifen. The side effects of tamoxifen include weight gain, hot flashes, decreased sexual desire or ability, and mood swings. The side effects occur more frequently in MBC patients than in FBC patients [12]. Our patients reported no side effects in relation to the administration of tamoxifen during the follow-up period. Because of the rarity of $\mathrm{MBC}$, the etiology of $\mathrm{MBC}$ is less clear than the etiology of FBC. The management of patients with $\mathrm{MBC}$ generally depends on the information from the diagnosis process and the treatments that are applied to patients with FBC. We are currently continuing to treat case 3 with tamoxifen (20 mg), while being careful to identify the occurrence of any adverse events.
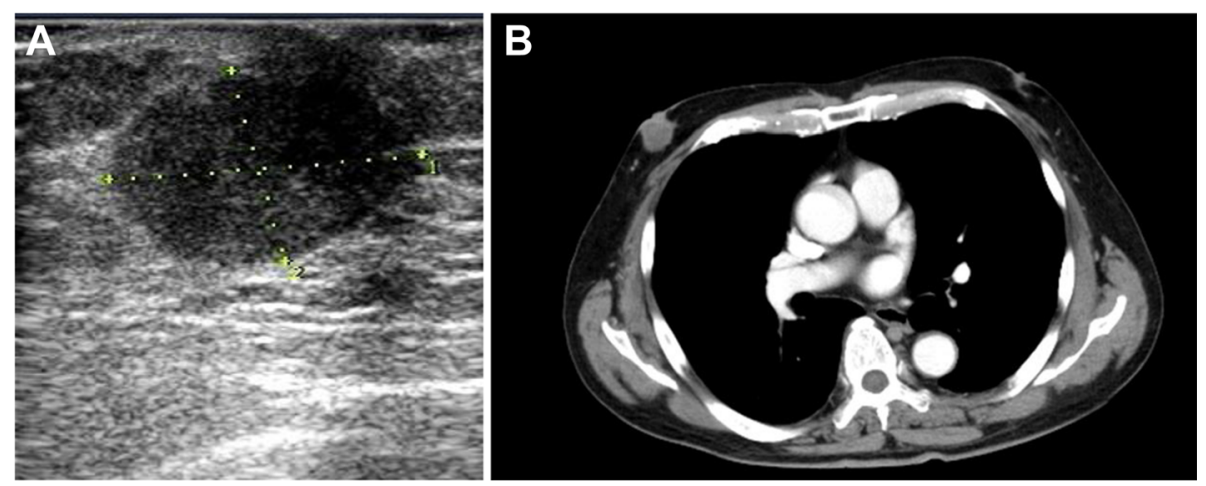

Fig. 3 a A preoperative US scan showing a round mass of $24 \mathrm{~mm}$ in diameter in the right subareolar area. $\mathbf{b}$ A preoperative chest CT scan showing a round tumor of $24 \mathrm{~mm}$ in diameter in the right subareolar area 
The prognosis of $\mathrm{MBC}$ had been reported to be worse than that of FBC. The reason for the lower overall survival associated with $\mathrm{MBC}$ is the higher age of susceptibility and the higher rate of cases who are diagnosed with advanced stage MBC [2]. When adjusted for the expected survival rate of the US population, race, gender, and age, no differences were found in the 5-year survival rate for $\mathrm{MBC}$ and $\mathrm{FBC}$. The 5-year survival rate at each stage of $\mathrm{MBC}$ vs. $\mathrm{FBC}$ is 96 vs. $99 \%$ (stage I), 84 vs. $84 \%$ (stage II), 52 vs. $55 \%$ (stage III), and 24 vs. $18 \%$ (stage IV), respectively [8]. Due to the lack of knowledge about MBC, patients may take longer to seek medical treatment after noticing, which may result in an increase in the tumor diameter [13]. Cases of MBC are often diagnosed due to the presence of a breast tumor [14].

In this case report, we performed mastectomy for all three patients. We usually explained the merits and demerits of the different procedures (including partial mastectomy or total mastectomy) to each patient. Although there were no statistically significant differences in the survival rates of the patients who underwent total mastectomy and partial mastectomy followed by irradiation, the local recurrence rate was higher in the patients who underwent partial mastectomy. To date, no studies have shown the superiority of the breastconserving surgery (BCS) for male patients. As a result, we select mastectomy with SLNB for our male patients. A simple mastectomy is the most common surgery for $\mathrm{MBC}$ patients, because it is associated with a lower rate of local recurrence rate in comparison to BCS [6]. Almost all male patients are treated with mastectomy, due to small volume of breast tissue in comparison to females. BCS for FBC patients is the standard therapy because it is associated with a lower level of mental anguish. In contrast, male patients show less mental anguish in association with breast loss. Furthermore, radiotherapy is necessary for BCS, which involves a long treatment period and increased medical costs. It is therefore reasonable to enforce mastectomy in MBC patients. There are no reports of differences in the incidence of postoperative complications in $\mathrm{MBC}$ and $\mathrm{FBC}$ patients. Generally, the rate of males who engage in manual labor is higher than that in females; therefore, the influence ALND is higher in $\mathrm{MBC}$ patients than in $\mathrm{FBC}$ patients.

ALND may be associated with scarring, axillary paresthesia, a decreased range of motion of the shoulder and arm, and lymphedema [15]. Although the usefulness of SLNB in female patients has been proven [16], it is difficult to establish the usefulness and safety of SLNB in MBC patients, but it is important to accumulate data. The patient who underwent ALND showed axillary paresthesia, a decreased range of motion of the shoulder and arm, while the other two patients who only underwent SLNB did not show any complications. As in FBC patients, SLNB is recommended for staging the axilla in $\mathrm{MBC}$ patients and is associated with fewer complications than ALND. Overgaard et al. suggested that the survival benefit after postmastectomy RT was substantial and similar in patients with $1-3$ and $4+$ positive lymph nodes in a subgroup analysis of randomized trials [17]. In case 3, we explained the potential survival benefit associated with radiation therapy after chemotherapy, but the patient refused to undergo radiation therapy because of the long-term nature of the treatment.

\section{Conclusions}

Although MBC is rare disease, a clinical trial is necessary to establish a standard treatment for MBC. In this study, three male patients with breast cancer were treated the same as female patients, and all patients remain alive without recurrence.

\section{Consent}

We routinely obtained general consent from every patient for using their clinical data before surgery. Written informed consent was not obtained from the patient for publication of this case report because this report is just a retrospective case report without additional invasive examinations or treatments for the study.

\section{Abbreviations}

ALND: axillary lymph node dissection; BCS: breast-conserving surgery; ER: estrogen receptor; FBC: female breast cancer; HER2: human epidermal growth factor 2; MBC: male breast cancer; PgR: progesterone receptor; SLN: sentinel lymph node; SLNB: sentinel lymph node biopsy.

\section{Competing interests}

The authors declare that they have no competing interests.

\section{Authors' contributions}

SS wrote the draft of the article. KS helped the final writing of the paper. SS, $M A$, and $Y T$ carried out the diagnosis of the tumor and the surgery of these patients. MK, $\mathrm{TH}, \mathrm{AO}$, and MM managed the preoperative general condition of the patient. All authors read and approved the final manuscript.

\section{Acknowledgement}

The authors would like to thank Dr. Brian Quinn for the critical comments of this manuscript.

Received: 16 June 2015 Accepted: 1 October 2015

Published online: 05 October 2015

\section{References}

1. Siegel R, Naishadham D, Jemal A. Cancer statistics, 2012. CA Cancer J Clin. 2012:62:10-29.

2. Nahleh ZA, Shikantiah R, Safa M, Jazieh AR, Muhleman A, Komrokji R, et al. Male breast cancer in the veterans affairs population: a comparative analysis. Cancer. 2007;109:1471-7.

3. Bureau of SocialWelfare and Public Health, Tokyo Metropolitan Government. http://www.fukushihoken.metro.tokyo.jp/iryo/iryo_hoken/gan_portal/ research/genjyou/shibousu.html. Accessed 21 May 2015.

4. Scott-Conner CE, Jochimsen PR, Menck HR, Winchester DJ. An analysis of male and female breast cancer treatment and survival among demographically identical pairs of patients. Surgery. 1999;126:775-80.

5. Cutuli B, Lacroze M, Dilhuydy JM, Velten M, De Lafontan B, Marchal C, et al. Male breast cancer: results of the treatments and prognostic factors in 397 cases. Eur J Cancer. 1995;31A:1960-4. 
6. Clarke M, Collins R, Darby S, Davies C, Elphinstone P, Evans E, et al. Effects of radiotherapy and of differences in the extent of surgery for early breast cancer on local recurrence and 15-year survival: an overview of the randomised trials. Lancet. 2005;366:2087-106.

7. Fentiman IS, Fourquet A, Hortobagyi GN. Male breast cancer. Lancet. 2006;367:595-604.

8. Giordano SH, Cohen DS, Buzdar AU, Perkins G, Hortobagyi GN. Breast carcinoma in men: a population-based study. Cancer. 2004;101:51-7.

9. Bloom KJ, Govil H, Gattuso P, Reddy V, Francescatti D. Status of HER-2 in male and female breast carcinoma. Am J Surg. 2001;182:389-92.

10. Rudlowski C, Friedrichs N, Faridi A, Füzesi L, Moll R, Bastert G, et al. Her-2/neu gene amplification and protein expression in primary male breast cancer. Breast Cancer Res Treat. 2004;84:215-23.

11. Muir D, Kanthan R, Kanthan SC. Male versus female breast cancers: a population-based comparative immunohistochemical analysis. Arch Pathol Lab Med. 2003;127:36-41.

12. Pemmaraju N, Munsell MF, Hortobagyi GN, Giordano SH, et al. Retrospective review of male breast cancer patients: analysis of tamoxifen-related side-effects. Ann Oncol. 2012;23:1471-4.

13. Petrek JA, Blackwood MM. Axillary dissection: current practice and technique. Curr Prob Surg. 1995;32:309-16.

14. Flynn LW, Park J, Patil SM, Cody 3rd HS, Port ER. Sentinel lymph node biopsy is successful and accurate in male breast carcinoma. J Am Coll Surg. 2008;206:616-21.

15. Lyman GH, Giuliano AE, Somerfield MR, Benson 3rd AB, Bodurka DC, Burstein $\mathrm{HJ}$, et al. American society of clinical oncology guideline recommendations for sentinel lymph node biopsy in early-stage breast cancer. J Clin Oncology. 2005;23:7703-20.

16. Ashikaga T, Krag DN, Land SR, Julian TB, Anderson SJ, Brown AM, et al. Morbidity results from the NSABP B-32 trial comparing sentinel lymph node dissection versus axillary dissection. J Surg Oncol. 2010;102:111-8.

17. Overgaard M, Nielsen HM, Overgaard J. Is the benefit of postmastectomy irradiation limited to patients with four or more positive nodes, as recommended in international consensus reports? A subgroup analysis of the DBCG 82 b\&c randomized trials. Radiother Oncol. 2007:82(3):247-53.

\section{Submit your manuscript to a SpringerOpen ${ }^{\circ}$ journal and benefit from:}

- Convenient online submission

- Rigorous peer review

- Immediate publication on acceptance

- Open access: articles freely available online

- High visibility within the field

- Retaining the copyright to your article

Submit your next manuscript at $\gg$ springeropen.com 